\title{
A CENTRALIDADE DO CONSUMO NA SOCIEDADE CONTEMPORÂNEA
}

\author{
BARBOSA, L.; CAMPBELL, C. (Org.). Cultura, consumo e \\ identidade. São Paulo: Editora FGV. 2006.
}

\section{Gustavo da Silva Tristão}

Mestrando do Programa de Pós-Graduação em Comunicação (PPGCOM) da Escola de Comunicações e Artes da Universidade de São Paulo (ECA-USP).

E-mail: gu.tristao@gmail.com

Em Cultura, consumo e identidade, os temas que dão nome ao livro são apresentados em uma coletânea de artigos, nos quais as combinações entre eles fornecem a tônica do que é discutido em cada seção. Assim, parte-se de considerações a respeito da evolução dos estudos do consumo nas ciências sociais, seguidas de uma discussão sobre a sociedade de consumo, a partir das quais são introduzidos artigos em que se exploram as conexões entre cultura e consumo, bem como entre cultura e identidade.

Numa perspectiva geral, os estudos sobre consumo passaram a ganhar relevância nos Estados Unidos e Europa entre os anos 1970 e 1980, período em que as publicações tratavam majoritariamente sobre temas ligados à sociedade de consumo, à cultura material contemporânea, aos comportamentos de compra e às formas de comercialização. Em outras palavras, como definem os próprios autores, os estudos destinavam-se a saber sobre o que e por que se consome, sendo que, à época, a perspectiva interdisciplinar tinha como foco as áreas do marketing, da comunicação e da antropologia.

No cenário brasileiro, segundo os autores, os estudos sobre consumo antes de 2006, ano de publicação do livro, eram recentes e privilegiavam etnografias de práticas e rituais de consumo, marcas e mercados. Até então, observava-se certa escassez de estudos sobre modos de vida dos grupos marginalizados no país, sendo em sua maioria produções que tinham a carência material como critério epistemológico central, a partir da negação do status de pertencentes à sociedade moderna e à sociedade de consumo. Tal constatação indica a necessidade de estudos que levem em consideração o mapeamento do padrão de consumo desses grupos para averiguar seu papel na ascensão social e nas construções identitárias, um dos eixos condutores do livro.

Ao mesmo tempo, os autores sinalizam a multiplicação de estudos profundos do consumo da classe média quanto a mediação, uso e fruição de bens materiais, campo profícuo quando se fala do Brasil contemporâneo. A mudança de postura em relação à importância atribuída ao consumo de tais classes, por sua vez, trouxe à tona temas importantes para a compreensão de seus sujeitos e contextos, como práticas, padrões e rituais de consumo de grupos, gêneros, religiões e faixas etárias. Isso aponta para as abordagens recentes que privilegiam um viés mais sociológico e antropológico, como os artigos que compõem o livro, em que os estudos do consumo guiam 
as discussões propostas, privilegiando sua compreensão enquanto processo social e mecanismo de mediação fundamental das sociedades contemporâneas.

Nessas sociedades, sob a perspectiva das ciências sociais, paira o que Lívia Barbosa e Colin Campbell chamam de a "maldição do consumo", em que o valor do trabalho é tido como moralmente superior ao do consumo. Enquanto o trabalho é considerado fonte de criatividade, autoexpressão e identidade, o consumo é tido como alienação, falta ou perda de autenticidade, um processo individualista e desagregador. Tal constatação expõe quanto as ciências sociais tendem a enxergar o consumo de bens supérfluos como uma atividade passível de culpa, e até mesmo o veem como um mal moral.

A ambiguidade do consumo é colocada em termos dos significados positivos e negativos que lhe são atribuídos, como o uso e a manipulação e/ou experiência, em oposição à ideia de compra, exaustão, esgotamento e realização. Entretanto, atualmente tem-se percebido que a simples aquisição de um bem através de compra não constitui mais um elemento para definir determinado comportamento social como consumo, sendo este agora visto como um processo complexo, dependente de inúmeras variáveis e passível de ser estudado sob novas abordagens. Assim, temos que, na sociedade contemporânea

[...] o consumo é ao mesmo tempo um processo social que diz respeito a múltiplas formas de provisão de bens e serviços e a diferentes formas de acesso a esses bens e serviços; um mecanismo social percebido pelas ciências sociais como produtor de sentidos e identidades, independentemente da aquisição de um bem; uma estratégia utilizada no cotidiano pelos mais diferentes grupos sociais para definir diversas situações referentes em termos de direitos, estilos de vida e identidades; e uma categoria central na definição da sociedade contemporânea. (p. 26)

A importância atribuída ao consumo para o entendimento da sociedade contemporânea abre caminho para a discussão proposta por Campbell em seu artigo "Eu compro, logo sei que existo", em que o autor elenca a emoção, o desejo e o individualismo, os quais guardam conexões com a cultura, como aspectos centrais do consumo moderno. Nesse contexto, os gostos pessoais referentes a música, moda, gastronomia e hábitos passam a caracterizar a individualidade, sendo a identidade algo a ser considerado segundo nossas reações aos produtos, e não neles em si, ou seja, o monitoramento dessas reações é um modo de descobrir quem somos. Logo, na sociedade contemporânea, o senso de identidade não é mais claramente determinado pela filiação do indivíduo e pela determinação de classe ou status de certos grupos, num processo em que a identidade passa a ser descoberta, e não comprada. Em vez de aprofundar a crise de identidade, como afirmam Bauman e outros autores, para Campbell o consumo se apresenta como um caminho para solucioná-la, ou, em outras palavras, como coloca o próprio autor, na sociedade moderna de consumo o indivíduo compra a fim de descobrir quem ele é.

O consumo moderno é apresentado como drama social por Laura Graziela Gomes sob a figura de Madame Bovary, protagonista do romance homônimo de Gustave Flaubert, em que o autor antecipa a percepção da importância do consumo para a subjetividade moderna. A personagem revela as principais características que o consumo adquire 
em nosso universo social atual, entre as quais a importância da vida interior como motor do desejo e sua consequente insaciabilidade. $\mathrm{Na}$ novela romântica, a personagem experimenta a imersão em um mundo interior de sonhos e fantasias, em que o "sonhar acordado" alimenta grande parte de sua interioridade, uma das características do indivíduo moderno em sua relação com o consumo. Esse prazer autoelusivo, ancorado em emoções, e não nas sensações produzidas pelos sentidos, revela Madame Bovary como o retrato da consumidora moderna, que explicita os mecanismos e as lógicas que orientam o consumidor contemporâneo. Assim, a história efetiva-se como drama social quando a heroína se afunda em dívidas e no adultério ao tentar transformar o mundo ao seu redor no material de seus sonhos.

A seção que trata das relações entre cultura e consumo é introduzida pelo artigo "Plásticos: a cultura através das atitudes em relação aos materiais artificiais”, de Tom Fischer, em que o autor investiga como os consumidores ingleses se comportam diante dos materiais plásticos. Segundo ele, as reações das pessoas às mercadorias são determinadas tanto por suas propriedades físicas quanto por suas associações simbólicas, verificando-se uma ambiguidade no que se refere à imagem do plástico, relacionada tanto à dimensão progressista positiva quanto à artificialidade negativa. A combinação entre essa imagem e o conhecimento popular derivado do contrato sensorial com o próprio material constitui, assim, uma resposta complexa dos consumidores. Nas reações e percepções das pessoas, Fischer constata que a noção de "nojo" desempenha função central. Destaca-se o fato de que nossas relações com bens e serviços são construídas levando-se em conta outros fatores além do gosto e da distinção social, estendendo a relação entre a atividade de consumir e os fatores sensoriais, emocionais e intelectuais que a envolvem.

No artigo seguinte, "Cultura, consumo e identidade: limpeza e poluição na sociedade contemporânea brasileira”, Lívia Barbosa expõe sua pesquisa sobre as práticas de higiene e de lavagem de roupas de mulheres brasileiras de diferentes segmentos sociais, que revela alguns pontos em comum com a pesquisa de Fischer. A autora frisa que a relação entre cultura e consumo é íntima e óbvia para a antropologia, evidenciada em sua pesquisa pela ligação clara entre o sistema classificatório de uma sociedade e suas relações com as práticas de consumo. Desse modo, tem-se uma reafirmação da constatação de Fischer de que nossas relações com o mundo material devem ser entendidas como um jogo entre aspectos físicos e simbólicos, em que a cultura material "comunica" ao nos fornecer informações sobre as pessoas e o mundo que as cerca, materializando as categorias da cultura. Assim como no artigo anterior, a noção de "nojo" desempenha função central nas atitudes das consumidoras quanto às práticas de lavagem de roupas, o que é confirmado pelo fato de a seleção de roupas a serem lavadas juntas, separadas, à mão ou na lavanderia ser orientada por um esquema classificatório segundo seu grau de poluição, influenciando a imagem da mulher perante o grupo a partir da adoção, ou não, de tal esquema com base em critérios estéticos e morais.

A última seção do livro trata de cultura e identidade a partir de dois artigos. Em "Nada além da epiderme: a performance romântica da tatuagem”, Maria Isabel Mendes de Almeida apresenta sua pesquisa etnográfica sobre a relação entre tatuagem, subjetividade e consumo. A tatuagem é colocada em termos de uma experiência estetizada, 
individualizada e prazerosa que imprime certa permanência ao efêmero, cujo estudo permite refletir sobre processos subjetivos de construção de identidades e de sua articulação com práticas de consumo, bem como conectar de maneira particular os planos interior e exterior dos sujeitos, onde a epiderme expressa a fronteira entre eles. A autora aborda a questão da tatuagem enquanto modo de recuperação da dimensão do vivido corporal e da busca da autenticidade, frisando que as formas de construção e de manipulação da identidade oferecidas pela tatuagem não se relacionam com a compra e o uso de mercadorias, mas com o fato de que a epiderme modificada serve como modo de afirmação de si mesmo. A pele, então, é tratada como meio de comunicação entre os mundos exterior e interior das pessoas, semelhante a uma tela virgem, pela qual se expressa a sensibilidade tanto estética quanto espiritual. Logo, a tatuagem configura-se como uma forma de expressar quem as pessoas "verdadeiramente são", construindo a manifestação da profunda urgência e primazia do sujeito entre as diversas maneiras de estetização da existência contemporâneas, a partir de cirurgias, cosmética e body building.

O último artigo, de Paulo Gabriel Hilu da Rocha Pinto, expõe a complexidade da questão da identidade a partir de pesquisa de campo desenvolvida na Síria. Em "Mercados de devoção: consumo e identidades religiosas nos santuários de peregrinação xiita na Síria”, o autor trata das relações entre peregrinações, práticas de devoção e consumo dos produtos religiosos a partir de sua etnografia, mostrando quão simplista é a suposta submissão do consumidor aos desígnios do produtor. Os significados atribuídos pelo produtor às mercadorias podem ser inteiramente diferentes daqueles atribuídos pelos consumidores, considerando-se que os objetos de devoção religiosa, quando transformados em mercadoria, mostram variadas formas de serventia. No caso dos suvenires, por exemplo, o autor ressalta a importância daquilo que chama de dimensão da experiência, em que as mercadorias adquiridas em peregrinações funcionam como lembranças turísticas, evocando a experiência vivida na mente do peregrino. Dada a heterogeneidade entre as diversas tradições islâmicas, que se espalham por vários países do Oriente Médio, o consumo de ícones religiosos materializados em mercadoria ajuda na criação e/ou consolidação de comunidades separadas geográfica e etnicamente. Em tais comunidades, a "mercadoria religiosa", dependendo do momento, pode ser vista como objeto sagrado ou profano, sendo que os peregrinos selecionam e combinam diferentes elementos de suas tradições religiosas no intuito de preencher e satisfazer suas necessidades devocionais em situações distintas.

Assim, o livro oferece uma valiosa análise das relações entre cultura, consumo e identidade a partir de atos de consumo cotidianos que, até pouco tempo atrás, tinham sua importância diminuída no ambiente acadêmico. De maneira bastante clara, a leitura permite captar as sutilezas e subjetividades envolvidas em tais atos, que se mostram essenciais para o entendimento da sociedade contemporânea e do papel central do consumo na pós-modernidade. Desse modo, a obra é capaz de fornecer insights oportunos para aqueles que se dedicam ao desenvolvimento de pesquisas ligadas à temática sob uma perspectiva que privilegia os determinantes culturais e identitários que orientam os atos de consumo na contemporaneidade, abrindo espaço para abordagens interdisciplinares capazes de ampliar e inovar as possibilidades de estudos no campo. 